\title{
O registro da aula: \\ a construção do processo de autoria nas aulas de didática
}

\author{
The class record: \\ the construction of the authoring \\ process in didactics classes
}

\author{
Helena Maria dos SANTOS* \\ Ronaldo Alexandre de OLIVEIRA**
}

\begin{abstract}
Resumo: Neste trabalho, objetiva-se apresentar a prática dos registros construídos pelos alunos a partir das aulas de Didática, como possibilidade de construção do processo de autoria sustentado nas atitudes de observação, registro e reflexão. Por intermédio do procedimento de análise de conteúdo, o material escrito pelos alunos de uma turma do quarto período do Curso Normal Superior da Universidade do Vale do Paraíba foi explorado e possibilitou a classificação desses documentos em três categorias: registros descritivos, registros descritivos-interpretativos, registros analiticos-reflexivos. Verificou-se que os registros considerados somente descritivos apontaram para uma formação baseada na racionalidade técnica, dimensão essa que deve ser superada pela necessidade atual de professores mais reflexivos e autônomos. Nas demais categorias, percebeu-se o quanto o ato de vivenciar, de observar, de registrar e de refletir sobre as aulas direcionam para uma dimensão do exercício reflexivo, extremamente necessário à educação contemporânea, marcada pela provisoriedade, instabilidade e incerteza. São esses componentes da contemporaneidade que requerem uma formação reflexiva, criadora e criativa, que são as bases da autoria.
\end{abstract}

Palavras-chave: registro, reflexão, formação de professores, autoria

\footnotetext{
* Mestre em Educação (Currículo) pela PUC/SP. Professora da Universidade do Vale do Paraíba - UNIVAP. Email: helenama@uol.com.br

** Doutor em Educação (Currículo) pela PUC/SP. Professor da Universidade do Vale do Paraíba - UNIVAP. Email: roliv1@uol.com.br
}

Olhar de professor, Ponta Grossa, 8(1): 39-49, 2005. 


\begin{abstract}
This work aims at presenting the practice of records being drawn up by students from the didactics classes, as a way of constructing a sustained authoring process in attitudes of observation, recording and reflection. The material, written by students in $a 4^{\text {th }}$ year class in the Regular Higher Course at the Vale do Paraíba University, was examined using a methodological procedure of content analysis, and enabled the classification of these documents into three categories: Descriptive Records, Descriptiveinterpretative Records and Analytical-reflective Records. It was noted that the records that were considered only descriptive, pointed towards training based on technical rationality, which must be surpassed because of the current need for more reflective and autonomous teachers. In the other categories, it was noted how much experiencing, observing, recording and reflecting on classes points towards a reflective dimension which is so necessary to contemporary education which is marked by impermanence, instability and uncertainty. It is these contemporary components that require reflective, creative and productive training which are the bases of the authoring.
\end{abstract}

Key words: record, reflection, teacher training, authoring

Os Registros de Aulas, definidos como "documentos em que os professores anotam suas impressões sobre o que vai acontecendo em suas aulas" (ZABALZA, 2004, p. 13), vêm sendo, cada vez mais, uma prática cotidiana para muitos professores que se propõem a refletir sobre sua prática, com o intuito de melhorá-la.

Articulado ao processo de reflexão sobre a prática, definido como uma "imersão consciente do homem no mundo da sua experiência" (GÓMEZ, 1997, p. 103), o Registro apresenta-se como uma forma de materialização desse processo de imersão consciente do professor, ao qual é possível recorrer quantas vezes forem necessárias.

De acordo com Weffort (1996), “ $a$ escrita materializa, dá concretude ao pensamento, dando condições de voltar ao passado, enquanto se está construindo a marca do presente". Podemos, pois, afirmar que a escrita, sendo um processo de construção, é, também, de autoria, uma vez que ela expressa o pensamento e as reflexões daquele que escreve para torna-los públicos.

Refletir e registrar são convites para sair de um estágio/tempo em que a prática de ensinar e aprender se centrava num ato mecânico de transmissão de saberes, a fim de atingir a possibilidade de criar dispositivos intelectuais para que professores e alunos estabeleçam relações entre aquilo que está sendo visto, estudado e refletido, com os saberes incorporados em outras situações de aprendizagem, possibilitando assim a construção de conhecimentos.

Pensar a construção do conhecimento a partir da prática reflexiva levanos a considerar o papel preponde- 
rante que assume essa atitude frente à construção da autonomia e, também, da possibilidade de vincular-se ao mundo de uma maneira mais crítica. Dessa forma, é possível olhar para o contexto social para nele podermos intervir, pois é nesse social que está o educacional, e transformá-lo implica, ao mesmo tempo, transformar o contexto, o mundo.

Dickel (1998, p. 42), a partir das idéias de Zeickner, aponta que a prática reflexiva somente tem sentido para os professores que desejam pensar sobre as dimensões sociais e políticas da educação e do contexto em que ela se insere, uma vez que "devemos favorecer as propostas que dispõese a transcender à exclusiva preocupação pela capacitação individual e pela transformação pessoal, incluindo também uma preocupação explícita com a reconstrução social" (ZEICKNER, 1995, p.397).

Essas idéias, apresentadas por Zeickner, fazem-nos pensar na diferença que faz a prática reflexiva na formação inicial de educadores, principalmente quando temos marcas de uma formação que esteve calcada, por muito tempo, na racionalidade técnica, em que o ato reflexivo estava distante das práticas pedagógicas.

Vivemos num tempo de incertezas, instabilidade e provisoriedade do conhecimento e sabemos o quanto essas questões dizem respeito ao oficio de educador, no ato de formar. Para Schön, existem zonas indeterminadas da prática e são exatamente essas zo- nas que não correspondem aos cânones da racionalidade técnica. "Quando uma situação problemática é incerta, a solução técnica de problemas depende da construção anterior de um problema bem-delineado, o que não é, em si, uma tarefa técnica" (SCHÖN, 1998, p.17).

Ainda, segundo Schön (1998), podemos ver o quanto a educação contemporânea busca por um modelo educacional, em que, no rol de objetivos previstos, estejam contemplados as metas que dêem possibilidades aos alunos de aprenderem a agir de forma competente em situações nos não existem respostas certas de imediato ou procedimentos-padrão.

Dessa forma, é impossível pensar numa educação que habilite os estudantes para tal fim, se insistirmos em trabalhar um modelo educacional em que se insista em se fazer do ato de aprender um ato mecânico, repetitivo e acrítico. A educação bancária, da qual nos falava Paulo Freire (1999), é o modelo que se faz necessário ser superado em função de processo de formação, para que o aluno possa se sentir sujeito da sua prática, construtor e configurador das suas idéias, o que, em nosso entender, leva à constituição do autor. Nesse sentido, acreditamos que o ato de registrar contém elementos capazes de ativar e desenvolver essa potencialidade em cada aluno que se predispõe a observar, registrar e refletir.

Sabemos que registrar não é uma atividade fácil. Exige, segundo 
Weffort (1996), "exercício disciplinado de persistência, resistência, insistência, na busca do texto verdadeiro". Essas ações se fazem necessárias, uma vez que foram negligenciadas durante todo um percurso de formação marcado por uma educação pautada pela racionalidade técnica. $\mathrm{O}$ ato de escrever exige do aluno uma consciência do não saber e uma prédisposição para exercitar, disciplinadamente, o observar, o registrar e o refletir. Ainda, segundo Weffort (1996, p. 43), o registro "obriga o exercício de ações - operações mentais, intelectuais de classificação, ordenação, análise, obriga a objetivar e sintetizar, trabalhar a construção da estrutura do texto, a construção do pensamento".

A idéia de trabalhar o registro na formação inicial e, também, no exercício da docência, leva-nos ao encontro da concepção do professor enquanto pesquisador, aquele que observa, reflete e registra aquilo que foi vivenciado. Essa postura contém ingredientes transformadores e modificadores da prática, uma vez que lida com a possibilidade de o próprio educador ser o sujeito da sua ação docente, configurando-se, assim, como aquele que pesquisa seu próprio fazer por meio do ato de observar, refletir e registrar.

$\mathrm{O}$ ato de refletir a partir do registrado, modificando idéias, leva, conseqüentemente, à transformação da própria ação, visto que existe um tempo reflexivo compreendido entre o momento da observação e do regis- tro, e aquele que se dá no momento em que se reflete sobre a ação. É no processo de reflexão sobre a reflexão na ação, que, segundo Schön (1995, p. 83),

é possivel olhar retrospectivamente e refletir sobre a reflexãona-ação. Após a aula, o professor pode pensar no que aconteceu, no que observou, no significado que lhe deu e na eventual adoção de outros sentidos. Refletir sobre a reflexão-na-ação é uma ação, uma observação e uma descrição, que exige o uso de palavras.

$\mathrm{O}$ educador precisa assumir-se como sujeito da sua prática e, também, da sua escrita, que não é neutra: é pensada, reelaborada, reorganizada, carregada de intencionalidades, contém marcas, pessoalidade, o que nos leva ao encontro do sentido daquele que confere autoria, que deixa marcado e vai marcando outros com suas opiniões, seus pensares e fazeres reflexivos, como nos aponta Weffort (1996, p. 41):

Mediados pelo registro deixamos nossa marca no mundo. Há muitos tipos de registro, em linguagens verbais e não verbais. Todas quando socializadas, historificam a existência social do indivíduo. Mediados por nossos registros, reflexões, tecemos o processo de apropriação de nossa história, a nível individual e coletivo. 
Esse ato de construir e, em muitos momentos, de reconstruir a história por meio do exercício de registrar e refletir a partir daquilo que foi visto, faz-nos pensar na possibilidade de reorganizarmos e compreendermos o próprio momento que vivemos na educação. Momento de instabilidade, complexidade e provisoriedade do conhecimento, o que nos leva a ter outras atitudes diante do contexto contraditório que se põe na contemporaneidade.

Nesse sentido, este trabalho objetiva apresentar a contribuição que a prática do registro das aulas de Didática oferece à construção de um espaço reflexivo, na própria aula, que possibilita a elaboração de dispositivos intelectuais para redirecionar e/ou transformar a prática docente. É essa nova postura que, no nosso entender, confere a autoria àquele(a) que utiliza a prática do registro.

\section{O REGISTRO NAS AULAS DE DI- DÁTICA: A CONSTRUÇÃODE UM PERCURSO}

Responsáveis pela disciplina Didática no Curso Normal Superior da Universidade do Vale do Paraíba UNIVAP, em São José dos Campos, interior de São Paulo, sentimo-nos impelidos a realizar, com os alunos das quatro turmas do $4^{\circ}$ período, a experiência do Registro das Aulas de Didática, ministradas, semanalmente, no segundo semestre de 2004.

Acreditando que a prática do registro é um instrumento de importan- te contribuição à formação e prática do professor, procuramos fazer, na primeira aula, uma breve sensibilização sobre a importância da prática do registro e, posteriormente, propusemos uma organização para que todas as aulas de Didática fossem registradas.

Para isso, preparamos uma lista contendo todas as datas previstas para as aulas de Didática durante o semestre, e, espontaneamente, os alunos inscreveram-se, optando pelo dia que fosse de seu agrado, para se responsabilizarem pelo registro. Tomamos o cuidado para que todas as aulas fossem registradas por um aluno.

É importante salientarmos que as turmas são compostas por uma clientela bastante diversificada. Na mesma sala de aula, encontramos alunos com uma larga e diversificada experiência no magistério, bem como alunos provenientes do Ensino Médio Regular. Conseqüentemente, os alunos com experiência profissional no magistério e com uma certa familiaridade com a prática de registro se prontificaram com mais espontaneidade do que os alunos que não têm experiência na docência.

A insegurança diante do compromisso de escrever os seus pensamentos e de apresentá-los, posteriormente, à classe não foi uma situação confortável para alguns alunos, mas, depois dos primeiros registros trabalhados em sala de aula, não foi difícil completarmos nosso cronograma, principalmente por não definirmos, a priori, nenhum modelo ou padrão para a cri-

Olhar de professor, Ponta Grossa, 8(1): 39-49, $2005 . \overline{43}$ 
ação do registro das aulas. O objetivo primeiro era que cada aluno enfrentasse a tarefa de fazer o registro de forma pessoal, expressando, por meio da escrita, o seu próprio estilo e o seu próprio pensamento.

A exploração desses registros durante o semestre deu-se da seguinte forma: iniciávamos cada aula com a leitura do registro da aula anterior e abríamos um espaço/tempo para a discussão dos aspectos considerados mais importantes pelo grupo. Esse procedimento exigiu do grupo disposição para a escuta da produção autoral do outro, e constituiu, para o autor, um desafio, uma vez que precisava submeter seu texto ao crivo crítico do grupo que, após a leitura, procurava sistematizar, em forma de discussões, os aspectos considerados pelo autor no registro da aula. Não se tratava de uma avaliação do Registro, mas de uma apreciação da elaboração acadêmica do outro.

No final de semestre, selecionamos, aleatoriamente, doze registros de uma das turmas, para serem analisados. De posse desses registros ${ }^{1}$, servimo-nos do procedimento metodológico de análise de conteúdo para explorarmos o material escrito, com o objetivo de "compreendermos, criticamente, o sentido das comunicações realizadas, seu conteúdo manifesto ou latente, as significações explícitas ou ocultas" (CHIZZOTTI, 2001, p.98), bem como percebermos o processo de construção da autoria, que passa da mera descrição da aula a uma reflexão sobre a aula.

\section{COMPREENDENDO A CONSTRU- ÇÃODOPROCESSO DE AUTORIA APARTIR DO REGISTRO DASAU- LAS DE DIDÁTICA}

No contato com os doze registros referentes às aulas de Didática, produzidos pelos alunos durante o segundo semestre de 2004, procuramos, para a análise do conteúdo, identificar os registros de 01 a 12, para salvaguardar a identidade de seus autores.

Realizamos, em um primeiro momento, uma leitura exploratória de todos os textos, com o objetivo de nos familiarizarmos com essas produções e de, concomitantemente, percebermos o estilo pessoal de cada autor no desenvolvimento de seu registro. Essa exploração possibilitou-nos caracterizar os textos, como um todo, da seguinte forma:

a) Registros descritivos: é o caso dos registros 07, 11 e 12, em que os autores procuraram, simplesmente, descrever os acontecimentos das aulas, em sua ordem cronológica, sem nenhuma inferência pessoal. Ou seja, desenvolveram relatos descritivos da organização e da seqüência das atividades que foram desenvolvidas no período da aula.

${ }^{1}$ Os registros estão sob a responsabilidade dos professores autores deste trabalho. 
b) Registros descritivos-interpretativos: são os registros identificados como 01, 04, 06, 08 e 10. Neles, além de descreverem cronologicamente, ou não, a trajetória das aulas, os autores apresentaram uma interpretação pessoal dos elementos trabalhados na aula. Ou seja, enriqueceram a descrição com comentários que expressaram sua maneira de compreender o elemento em questão.

c) Registros analiticos-reflexivos: enquadram-se nesta classificação os registros 02, 03, 05 e 09, cujos autores procuram expressar uma análise crítica dos elementos trabalhados em sala de aula, sem considerar a ordem cronológica dos acontecimentos. Além de realizar a transposição desses elementos para a sua formação profissional, eles apresentaram construções textuais autônomas, o que chamamos de processo de autoria a partir das aulas, enriquecidas, inclusive, com citação de outros autores.

Após essa leitura exploratória, retomamos cada registro e, em várias leituras, mais minuciosas, procuramos identificar os elementos mais relevantes em cada texto. É importante salientarmos que tais elementos foram encontrados nos registros caracterizados como descritivos-analíticos e nos registros analíticos-reflexivos. Isso demonstra o quanto os registros descritivos relatam, fielmente, a trajetória dos acontecimentos das aulas, confirmando o que foi, anteriormente, afirmado por Weffort (1996), a respeito da dificuldade pessoal em de- senvolver registros reflexivos.

Para fins de análise desse conteúdo, procuramos categorizar os referidos elementos em três blocos temáticos, assim definidos: o que diz respeito à aula de Didática e ao professor, o que diz respeito ao confronto pessoal vivenciado a partir das aulas de Didática, e o que diz respeito ao movimento de construção teórica a partir da reflexão sobre a aula, ou seja, o processo de autoria.

No que diz respeito à aula de Didática e ao professor, os registros apontam o quanto os alunos se sentem livres e autônomos para expressarem suas opiniões e reflexões referentes à aula, ao conteúdo trabalhado e à metodologia utilizada pelo professor.

Avaliar, criticamente, a aula e a postura do professor, e expressar, publicamente, suas opiniões e reflexões por meio da escrita é, por um lado, um importante indício da construção da autoria e da autonomia frente ao que lhes é apresentado na disciplina de Didática. Por outro lado, esses registros manifestam uma consciência do processo de formação dos alunos, a ponto de, eles também se sentirem livres para considerar o que está contribuindo, ou não, para tal processo, o que significa uma postura ativa frente ao que lhes foi proposto nas aulas de Didática.

No que diz respeito ao confronto pessoal, vivenciado a partir das aulas de Didática, percebemos o quanto os alunos sentiram-se à vontade para 
manifestarem nos registros, os seus dilemas frente ao conteúdo e à metodologia trabalhada na disciplina de Didática. Tais dilemas são de diferentes natureza; por isso, procuramos categorizá-los para que nossa compreensão seja facilitada.

$\mathrm{O}$ primeiro dilema diz respeito à comparação das construções conceituais, das reflexões, das teorias, das discussões propostas nas aulas de Didática, no Ensino Superior, com as informações anteriormente recebidas em outros níveis de formação - como no magistério, por exemplo. Tal comparação demonstra, por um lado, a consciência do quanto o conhecimento está em contínuo processo de construção e, por outro lado, uma certa insatisfação com a disciplina de Didática desenvolvida no magistério, que acentuou, enfaticamente, o “como fazer", mas não se preocupou em fornecer instrumentos para pensar no "que se faz" e "por que se faz" em sala de aula.

O segundo dilema apreendido dos registros diz respeito ao confronto entre a aula de Didática e a própria postura do aluno enquanto futuro educador. Em diversos momentos, deparamo-nos com relatos em que os alunos apresentam verdadeiros "exames de consciência", evidenciando o auto-questionamento e a auto-análise de suas futuras práticas a partir dos conteúdos trabalhados em Didática. É interessante perceber que os registros desses "exames de consciência" estão sempre voltados para uma to- mada de decisão que aponta para um maior comprometimento profissional, ou seja, manifestam uma insatisfação com a mediocridade profissional.

O terceiro dilema, evidenciado nos registros, diz respeito ao movimento de contextualização da aula de Didática às realidades exigentes que os alunos vivenciam nas escolas da rede pública e particular no município de São José dos Campos. Esse movimento nos mostra o quanto a alternância entre os espaços, valores e crenças da Universidade e da Escola é um trânsito livre realizado pelos alunos, na certeza de que um não anula o outro. Porém, estando no Curso Normal Superior, eles procuram melhorar, cada vez mais, a sua prática.

Finalmente, no que diz respeito ao movimento de construção teórica a partir da reflexão sobre a aula, ou seja, o desenvolvimento de um processo de autoria, evidenciamos que os alunos manifestam suas autorias em diferentes direções, marcadas pela tentativa de definição de alguma idéia, de comparações entre considerações teóricas e situações da prática, e de críticas que afirmam posturas coerentes a serem construídas pelos professores.

A tentativa de definição de algum paradigma mostra uma autoria pautada na descrição de suas idéias a partir de um processo de interpretação, em que o aluno se sente livre para escrever e tornar público sua forma de expor seus pressupostos. Como, por exemplo, a definição de planejamen- 
to, evidenciada por um aluno em seu registro:

"Planejamento, ao meu olhar, é uma linha paralela entre a reflexão e a organização, e acima de tudo um ato de respeito ao aluno." (Registro 05).

No que diz respeito às comparações entre considerações teóricas e situações práticas, os alunos manifestam, em sua autoria, a necessidade de uma "libertação" dos conceitos solidificados e condicionados no cotidiano da prática, para atingirem posturas e práticas consideradas "ideais" no processo pedagógico, como mostra a construção apresentada por um aluno em seu registro, afirmando o que deve ser uma sala:

"Esta aula me levou a refletir sobre a minha sala de aula, acreditando que mais que um espaço, a sala de aula é um meio onde acontece o ensino-aprendizagem, e deve ser um ambiente confortável, atraente e alegre, proporcionando aos alunos liberdade de sugerirem, criarem, opinarem, criticarem, pois assim se realizará a verdadeira integração das crianças no ambiente sala de aula, transformandose em um espaço de crescimento integral." (Registro 04).

Em relação às críticas que ressaltam posturas coerentes a serem construídas pelos professores, os alunos mostram, em sua autoria, um elevado grau de exigência para com os professores e suas práticas pedagó- gicas. A liberdade com que tais exigências são apresentadas em seus registros evidencia a necessidade de maior comprometimento do professor com a sua profissionalidade, como mostra a parcela de um registro:

"É necessário clareza, e o fator da observação do contexto no qual o aluno está inserido propicia esclarecimentos maiores, frisando que a improvisação precisa ser controlada, pois a minha Didática é intencional, mas o não planejar é fundamental para o desenvolvimento de um professor incompetente." (Registro 09).

\section{CONSIDERAÇÕES FINAIS}

Ao perpassar pela experiência relatada sobre os olhares críticos e reflexivos dos alunos, por intermédio dos registros, deparamo-nos com múltiplas questões que abarcam a formação de um sujeito autor.

A primeira delas, que destacamos, é a própria reflexão que desenvolvemos a partir do currículo da disciplina de Didática, incorporado ao currículo do Curso Normal Superior, pensado como uma prática transformadora. Percebemos, nessa reflexão, a possibilidade de desenvolver uma atividade dessa natureza, uma vez que o próprio currículo da disciplina favorece uma experiência autoral dos professores que a ministram.

A segunda questão, que diz respeito à prática reflexiva do registro, 
denota uma criticidade e uma capacidade de criar instrumentos intelectuais que, por sua vez, instrumentalizam o fazer pedagógico para uma intervenção e transformação no contexto social educacional. Essa atitude representa, de uma certa forma, a superação da educação pautada na racionalidade técnica, uma vez que a educação contemporânea é marcada pelo provisório, o incerto e o instável.

Uma terceira questão aponta para a autoria, vista aqui como uma construção advinda do ato de registrar, do exercício reflexivo na cotidianidade docente. Contudo, essa autoria exige uma rigorosidade frente ao ato de escrever, que se expressa no processo de observação e participação das aulas, nas anotações feitas em sala, na retomada dos rascunhos, na reorganização do pensamento, nas opções e na organização dos registros frente aos elementos anotados. Ou seja, é a consolidação do olhar individual frente ao que foi vivenciado coletivamente.

Nesse momento de registrar, reflexivamente, é importante considerar a necessidade de distanciar-se da ação ocorrida em sala de aula, reaproximando-se dos rascunhos, resgatando a memória de diversas maneiras, desde aquelas que são explícitas nos rascunhos até as inauditas, mas que foram sentidas, vistas e vivenciadas por falas, gestos, atitudes e diferentes posicionamentos que podem ser interpretados no momento da reflexão sobre a ação.
Uma quarta questão diz respeito à socialização da materialização dessas memórias, sob a forma de registros. Tornar pública essa produção em sala de aula, por um lado, é o próprio enfrentamento crítico-interpretativo do registro, frente ao olhar julgador da coletividade representada pela sala de aula. Por outro lado, exige uma profunda atitude de abertura, respeito e escuta com os diferentes olhares que compõem a sala de aula.

Uma quinta e última questão diz respeito ao exercício do registro na aula de didática, enfrentado nessa dimensão. Esse exercício possibilitounos vivenciar a dimensão dialógica da educação, redimensionando, na sala de aula, a relação professor-aluno, uma vez que o aluno, ao registrar e tornar público o seu registro, evidencia a profissionalidade docente de quem coordena a aula e a capacidade de mediação desse profisssional.

Nesse sentido, o exercício do registro desenvolvido nas aulas de Didática, como possibilidade de um ato autoral, está intrinsecamente vinculado à capacidade do professor em mobilizar, interna e externamente, a si mesmo e aos seus alunos, possibilitando que a sala de aula seja um espaço para o exercício persistente e laborioso da criação, espaço próprio do autor e da autoria, que é processo, que se aprende, que se sistematiza. 


\section{REFERÊNCIAS}

CHIZZOTTI, A. Pesquisa em ciências humanas e sociais. 5 ed. São Paulo: Cortez: 2001.

DICKEL, A. Que sentido há em falar em professor-pesquisador no contexto atual? Contribuição para o debate. In: GERALDI, C. M. G. et al (Orgs.). Cartografia do trabalho docente: professor(a) pesquisador(a). Campinas: Mercado das Letras, 1998.

FREIRE, P. Pedagogia do oprimido. 27. ed. São Paulo: Paz e Terra, 1999.

GÓMEZ, A. P. O pensamento prático do professor: a formação do professor como profissional reflexivo. IN: NÓVOA, A. (Org.). Os professores e a sua formação. 3. ed. Lisboa: Publicações Dom Quixote, 1997.

SCHÖN, D. A. Educando o profissional reflexivo: um novo design para o ensino e a aprendizagem. Porto Alegre: Artmed, 1998.

Formar professores como profissionais reflexivos. In: NÓVOA, A. Os professores e sua formação. Lisboa: Dom Quixote, 1995.

WEFFORT, M. F. (Org.). Observação, registro, reflexão. São Paulo: Espaço Pedagógico, 1996.

ZABALZA, M. A. Diários de aula: um instrumento de pesquisa e desenvolvimento profissional. Porto Alegre: Artmed, 2004.

ZEICHNER, K. M. Los profesores como profesionales reflexivos y la democratización de la reforma escolar. In: CONGRESSO INTERNACIONAL DE DIDÁCTICA: VOLVER A PENSAR LA EDUCACIÓN, LA CORUNA. Anais..., Madrid: Morata. 1995.
Encaminhado em 17/03/05

Aceito em 11/05/05

$$
\text { Olhar de professor, Ponta Grossa, 8(1): 39-49, 2005. } \overline{49}
$$

